\title{
Linking Creative Processes with Personal, Vocational and Academic Development in Cross-Disciplinary Workshops
}

\author{
Christina Reading, Jess Moriarty \\ Faculty of Arts, School of Humanities, University of Brighton
}

\begin{abstract}
Understanding students' creative process in order to identify meaningful ways to nurture, support and develop creative practice students and enhance teaching and learning is a major challenge within Higher Education (HE). This paper evaluates a research project that studied creative writing and visual practice students' experiences of creativity at the University of Brighton. By providing opportunities for students to identify the things within their experiences, memories and even within themselves that inspire their creativity, the study found that it was possible to effectively support their creative processes. By developing workshops that helped to improve students' confidence and ownership of ideas, and create spaces in which to discuss their creativity away from their assessed work, this project aimed to provide a model of best practice that would enhance students creativity and their personal, vocational and academic development. The paper argues that students' creativity is best supported by embedding workshops into the curriculum that provide opportunities for students to gather the confidence and motivation to discuss their creativity and the factors that inspire it. The authors use their own experiences with creative practice and academic work to suggest that these workshops should also be embedded in HE as staff development.
\end{abstract}

\section{Introduction}

"They [academics] started to question why university life had to be that way, why they had to be removed from their work, why only certain forms of discourse counted as knowledge, why they didn't feel more connected to those they studied, why their mind should be split from their body, why they had to keep their emotions in check, why they could not speak from the heart.” [25]
In the above quote from 'A Methodology of the Heart: Evoking academic and daily life' [25], Professor Ronald Pelias challenges the notion that academic work must remain traditional and objective and suggests that some academics are frustrated by their inability to link the personal and emotional with the professional and academic. An important aspect of this paper will be to explore the relationship between creative practice and personal, vocational and academic development, in undergraduate students and also in the experiences of the authors as we are both creative practitioners and academics. Because the paper is talking about personal experiences and how they are linked to creative practice and academic work, this paper will deviate from the traditional objective academic writing style and presents itself in the first and second person where appropriate. The voice of the second author is in italics in order to differentiate from that of the first author.

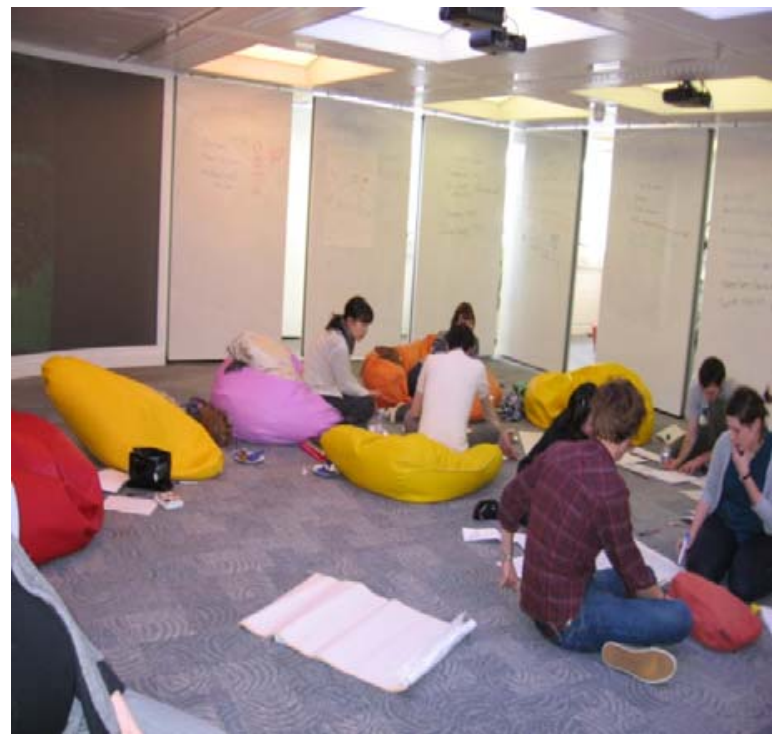

Figure 1. Students at work 


\section{Motivations}

When I joined the University of Brighton in 2004 as a part-time lecturer in Creative Writing, I felt like a fraud. I kept waiting for a colleague or a student to stop, point and declare me unfit as a lecturer, as an academic, as a researcher, and as a writer. The problem was that while I enjoyed my work, I still had no clear sense of who I was as a lecturer. I felt as if I had to 'become' an academic and that this would involve a rigorous apprenticeship. I was waiting for the tools to begin my metamorphosis: perhaps they would be handed to me by a superior lecturer? It was evident that there was no induction programme or explicit institutional support to help me to emerge from my chrysalis and being unable to marry my creative practice with my academic work was a cause of anxiety that ultimately resulted in academic writer's block.

In a similar way, when I joined the University as a researcher into creative practice in November 2005, although I understood intuitively that the two were linked I experienced a feeling of my own creative practice in photography and painting existing in a separate world from my work as an academic. My desire to reconcile these two aspects of my work was in part what motivated the research for this project.

I was working on a project for the Centre for Excellence in Teaching and Learning through Design (CELTD) investigating students use of museum collections as sources of inspiration for their creative practice and found that students often used autobiographical experiences as staring points for their own work but sometimes found it difficult to locate these personal concerns within wider academic and contextual debates [21].

I have addressed these complexities directly in my own practice based doctoral work, seeking to develop methodologies that allow for personal and autobiographical writing, research and making that make a distinctive contribution to practice based research [22]. I explored these challenged in research addressing the doctoral learning journeys of creative practice students finding that even at this level, students, although often inspired by autobiographical experiences, were uncertain how to acknowledge these starting points within their academic work [2].

\section{Background}

This frustration of linking autobiographical experiences and vocational and academic work was also evident in our students. The feedback from the National Student Survey suggested that they were unable to make links between what was being studied in the classroom and their ambitions post- university and that for some students this was demotivating. The inspiration for creative work is often located in personal memories and creative practice is often a way to understand the world and locate ourselves within it. This is particularly evident in creative practice students who tend to employ a form of 'autobiographical knowing and personal feelings, experiences and opinions' [17] to make sense of their discipline and its place in the world beyond the classroom. In this way, creative practice is directly connected to our personal, vocational and academic development but how to make this explicit was problematic. In 2007 I took part in a project at the University of Brighton to implement Personal Development Portfolios (PDP) with the aim of enabling students to make links between the skills they were acquiring in the classroom and their postuniversity ambitions. Ultimately the project failed as students and staff thought that the PDPs were patronising and meaningless [23].

This problem is also evident in staff development for academics who struggle to link lived experiences with legitimate academic work. In March 2007 I cofacilitated a series of writing retreats for academics from the Universities of Brighton and Sussex. A colleague and I had discussed our own problems with academic writing and how confidence and issues of limited time and crowded working spaces often increased the frustration of writer's block and dwindled levels of motivation [1]. Building on the work of others in the field, we applied for funding from the Centre for Excellence in Teaching and Learning (CETL) in creativity and were able to run one residential and one non-residential retreat that used creative writing methods to build confidence and passion with writing.

I was shocked and comforted to learn that many of the participants, regardless of position or status at the university, (professors, heads of department and newcomers like myself), nearly all struggled to write with absolute confidence when it came to academic research. The main difficulty seemed to be between the academic and the creative/personal voice. One participant compared the two by saying, "it's [academic writing] a highly controlled fantasy where people have no emotion and where writing is a highly genred and sort of yeah, academic writing is Halal, the blood is taken out of it whereas (creative) writing, the blood is left in.” [20]. It seemed that like me, many academics despite working hard on research projects and on reports, when it came to writing up the data felt as if they were obliged to take on a voice that did not sound like their own, that their academic writing voice was separate to their personal voice and that for many, this was problematic and contributed to a lack of motivation with the writing process: 
'the voice that I use in academic mode, is it mine, or is the voice of my profession, my 'ought to' voice, the voice that I've been taught to use? The voice I use today, it is my own; I recognise in it myself, the person who is really me. To find again that voice restores to me myself, it makes me whole, it wakes me up. Oh that I could reconcile those two voices to be me, myself in every situation'. And I suppose that's how I felt. Dee, Principal Lecturer (Jess Moriarty, 2007, p. 14)

I suppose this is a development from your retreat which was really good...there was a thing about for me about being real erm versus being I don't know being pretend. You have to make so many compromises, don't you? Miles, Principal Lecturer (Jess Moriarty, 2007, p. 14)

Since 2007 I have continued to run staff development workshops and attempted to facilitate personal, academic and vocational development by embedding it in teaching and learning practice. This paper argues that by embedding creative workshops into the curriculum for creative practice students and providing similar opportunities for academic staff as part of the university's staff development strategy, that it is possible to link academic, vocational and personal development for students and staff.

There is limited understanding surrounding how creative practice students learn from the sources that motivate and inspire them [4]. What is known is that in creative practice, autobiographical experiences and memories play an important part in supporting the creative process and students' understanding and engagement with their discipline is based on their previous knowledge and experience [3] and yet many students feel that they are at university to 'become' a creative practitioner, they seem unable to accept that this process is rooted in their lives preundergraduate study and make connections between their personal experiences and their assessed work. Within existing literature there is extensive debate about whether creativity resides in 'the person, a process or an outcome'[14], if it is the student, the study of the discipline or the assessed creative outputs that most effectively demonstrates how creativity can be affected and hopefully enhanced through undergraduate study and more generally, the Higher Education (HE) experience. This paper argues that whatever the source, supporting students to identify their own processes and products within their creative practice can help to add value to their learning experience and equip them with relevant skills for working in the arts and related vocations.

Within learning and teaching, current discourse suggests that all students bring their unique identities and personal life experiences to the construction of knowledge [8]. Undergraduate students take what is taught in the class room and use this as a means to contribute to and enhance their construction and understanding of their discipline. This understanding has its basis in previous knowledge and experience that their time at HE will hopefully build on, helping them to achieve a professional standard and skills base [3]. In this sense, all learning is personal and depends upon the learners' underlying beliefs, values and attitudes guiding their engagement with their studies.

For creative practitioners, writers and visual artists, personal interpretations of personal, social and cultural experiences are often the principal driving forces behind their creative processes. In writing, as in all creative practice, "When we (artists) sit down to write fictions, we may also hope to discover something about ourselves on the way" [24]. Not only are the motivators and inspirations for creative work often embedded in our autobiographical experiences, memories and sense of the world but the practice itself enhances our personal development.

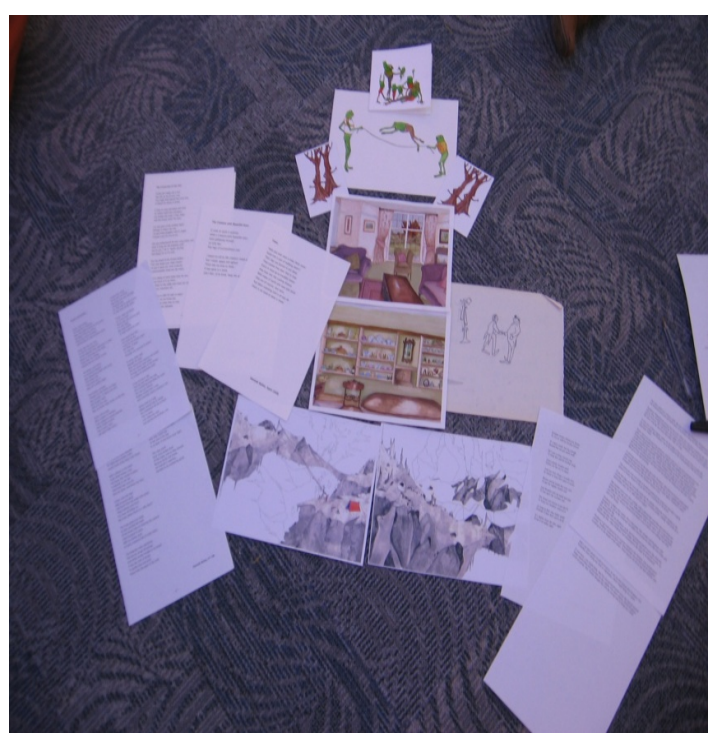

Figure 2. Student work 
Nurturing creativity is supported by recognition of the fact that "it is a very personal act" [18]. For this reason, it is connected to students' intrinsic motivation for learning and equipping them with the confidence and skills to critically reflect on their processes at work in their own creative practice. The process of constructing and articulating these personal interpretations and tapping into these intrinsic motivations however has become more problematic in $\mathrm{HE}$ as individual identities have become more fragmented and less anchored [26] than in previous generations. Today's learners arguably face increasingly complex choices and decisions about how to construct meaning in their lives [19]. This shift has caused Baxter Magola [9] to argue that; ' the central goal of higher education is to promote the internal capacity in students to chose their own beliefs, values, identity and relationships.' In this changing scenario, the challenge for creative practice students is developing the confidence and skills to articulate their creative process and the criteria that underpin it.

This paper argues that mobilizing some aspects of threshold theory [29] might be helpful for enabling students to articulate their creative process and related ideas. There is the potential for self reflective practice to become a powerful tool for enabling creative practice students to identify the barriers or stuck places in their own creative process and the factors that motivate and inspire them. A strong reflective practice might also be important for holding students through the liminal spaces or stages of not knowing indentified in threshold theory. Orsini - Jones (2008) argues in relation to her study of students learning French that 'to enable students to cross thresholds it is necessary to devise student centered activities that allow them to engage both in individual and collective reflection on the troublesome knowledge encountered. The overcoming of stumbling blocks will be greatly helped by the opening up of a dialogue between students and tutors and amongst students themselves' [6].

This paper argues that for creative practice students in particular, the ability to develop a critical form of self awareness through the development of self reflective practice is essential to improving the quality of their academic work. Helping students to locate themselves within their discipline and understanding the place of their discipline within the wider world can increase confidence, enabling them to evolve as students.

This approach requires reflective practice and provides a space for students to engage in a dialogue with their meta memories and meta cognitive processes [16]. This practice of reflection provides an opportunity for students to 'critically reflect, edit and refine a position' (Eisner: 2001.) that may lead to an enhanced sense of self within their academic work and a more definite awareness of their place within their discipline.

The best place for this type of reflection may not be within the classroom or while commenting on creative outputs for the purposes of assessment. Csikszentmihalyi [10] argues that this effective reflection in creative practice requires both 'involvement and detachment' meaning that practitioners must be effectively engaged in the work during the process of generating and making material. This active and involved time must be followed by equally dynamic periods of detachment characterized by extensive reflection in which the critical position and aesthetic qualities of work are considered. This time of objectivity can help creative practice students to feel less personally attached or enmeshed in their creative work, making the feedback process a less vulnerable and more constructive experience that can help them to develop as a practitioner. Establishing opportunities for reflection outside the classroom is therefore essential if the $\mathrm{HE}$ experience is to have a meaningful impact on creativity.

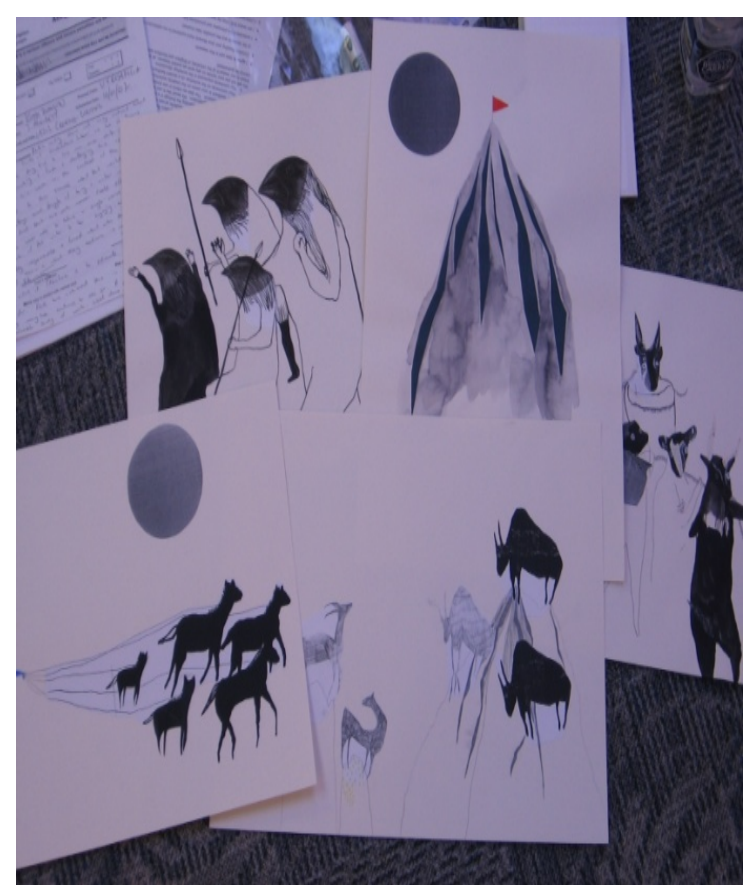

Figure 3. Student work

Supporting students' creativity is generally viewed as best achieved through a process based approach to learning and teaching [18], [11], [12]. At this stage the focus is on the student's experience of 
learning rather than the content or outcomes of learning. Biggs [3] proposed that creativity is best supported by approaches that improve students' ability to reflect on their ideas. Enabling students to make 'learning leaps' [29] to recognise and cross conceptual and skills thresholds in their creative practice is central to this project. This paper considers that in facilitating tutor:student and student:student discussions that explore autobiographical experiences with the creative practice will help creative practice students to evolve as informed learners and practitioners.

Creative practice students need to develop, 'develop self-efficacy, encourage risk taking in safe environments and help students engage in messy/complex processes in unpredictable situations which have no right or wrong answer' [18]. HE needs to create learning environments that will help students to evolve in this way by providing them with time and space outside the traditional classroom to discuss their experiences, motivations, barriers and general process in supportive cross-disciplinary groups. We suggest that these spaces have the potential to enhance students' creativity and facilitate their personal, vocational and academic development and that there is also the potential for using this model of best practice in staff development to help academics working in creative practice to marry their academic, vocational and personal development.

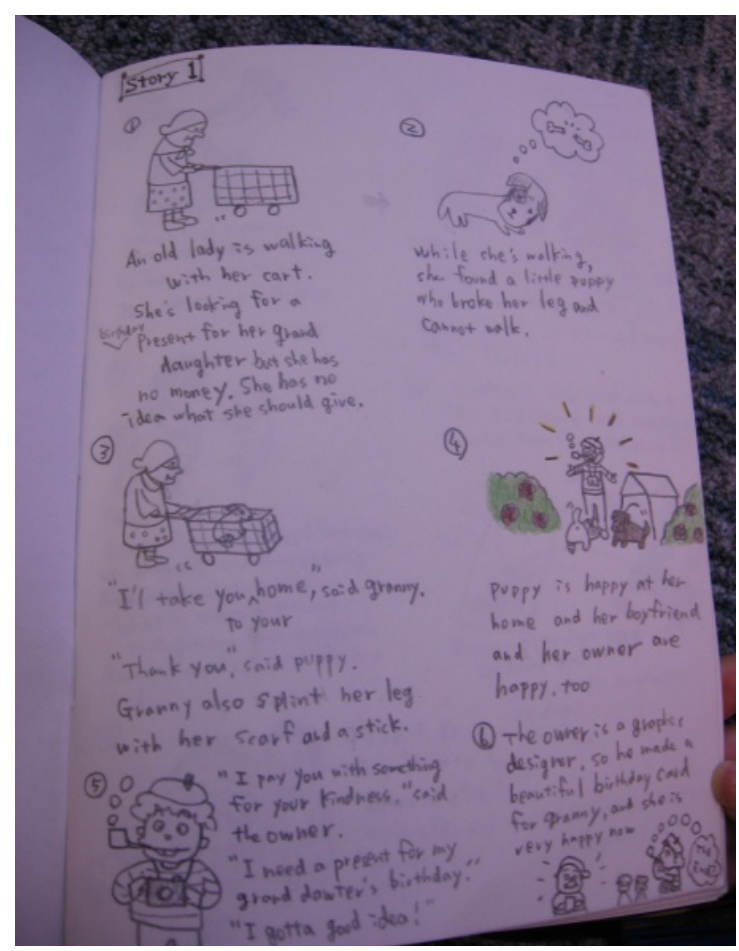

Figure 4. Student work
The research project was made possible by funding for a small research fellowship awarded by the Centre for Excellence in Creativity based at the University of Brighton. Through the project we aimed to develop a model of good practice that would be helpful for undergraduate students and staff at HE.

\section{Data Collection}

Data was collected in two stages. In the first stage undergraduate students on the Illustration degree from the School of Arts and Architecture, and students who had taken a creative writing module in the School of Humanities were invited to be interviewed about their creative practice. The interviewers asked students to reflect on their creative processes and inspirations in relation to their academic studies and how (if at all) this linked to their personal development.

In the second stage, having taken part in the interviews, the students were then invited to voluntarily attend a one-day workshop (a collaborative workshop for creative writing and visual practice students) to explore and discuss their sources for inspiration and to share their creative products. The insights provided by the interviews were used to design and facilitate a workshop to support students' creativity. The students took part in a variety of writing and drawing exercises, working individually and in small groups that combined the disciplines. They were also asked to discuss a number of questions relating to their creativity and personal motivations. These included:

1. What conditions are conducive to your creativity? 2. What does it mean to be creative and what is the effect of this on your academic studies and life skills?

3. What have been the effects of collaboration? How can you take this further?

By taking part in these exercises, we aimed to create opportunities for students to reflect on their creative work and to make the links between the seemingly intangible thing that is creativity and their academic and personal development. Students were asked to reflect on their experience of explicitly exploring and connecting with their creativity and how this might help them with their studies. In a third stage students were also asked to complete evaluation forms of feedback on their experiences.

\section{Data Analysis}

The data was analysed in order to discover similar and unique themes and ideas that emerged 
from the interviews with the undergraduate students. The main aims of our analysis were:

1. To collect reports of students' experience and perceptions of the barriers and motivators to their creative process through individual interviews and cross disciplinary group discussion.

2. To enhance students' awareness of their ongoing personal development and the skills they are acquiring in Higher Education via informal structured learning events (Cross 2006).

3. To develop a model of good practice for embedding personal development in a way that is relevant and meaningful to creative practice students and underpins their meta-cognition.

These autobiographical accounts were used to analyse the following aspects of the students' experience:

1. To identify the specific mechanisms for creativity within these particular groups of students that were unique to each discipline and also identify more generic experiences that support students in being creative.

2. To use these personal conversations to identify circumstances and material that empowers the creative process.

3. To identify potential blocks to students' creativity and to make use of their comments to suggest possible strategies to support students in overcoming these barriers.

4. To examine the attributes, processes and outcomes of creativity through the experience of the individual.

5. To identify the differences in student's approaches to their creativity, highlighting the barriers they experience and pinpointing those approaches that seem to be the most productive.

6. To understand how students' creativity and experiences with their creative process helped prepared them for work and for life beyond university.

\section{Results}

Feedback from the individual interviews and the evaluations of the collaborative workshop suggests that;
A) That the students found the experience of participating in the individual reflective

\section{interviews and the collaborative workshop positive.}

1. The interviews and the workshop were able to raise students' awareness of their ongoing personal development and enabled them to identify the skills that they are acquiring in $\mathrm{HE}$ and consider how these might relate to their post-degree ambitions.

2. Students found that the opportunity to discuss their creative process on a one to one basis was useful and enjoyable. Students said that these personal conversations with a researcher provided them with an opportunity to discuss and describe their creative process in-depth and outside the assessment criteria and the traditional formal setting of the classroom. Because the process was one to one and non-judgemental or assessed, they were able to reflect honestly about the positive and nonpositive experiences and talk at length about why they were proud and/or concerned about their progress. Each interview provided opportunities for the students to identify their own processes and to consider how they were developing as practitioners and learners which was motivational.

The students' enjoyed participating in the Creativity Workshops and found that it was a beneficial opportunity to discuss and debate their creativity in an informal setting, outside their normal learning environment. Students also found that working on collaborative, interdisciplinary tasks using a variety of drawing and writing enhanced their creative processes.

The collaborative workshops provided students with the opportunity to work with students from another creative discipline. These cross-discipline activities, writing poetry, collage and sketching, provided further opportunities for students to engage in discussion and debate their creativity which gave them a surer sense of their position within their discipline and a greater sense of how they were evolving as practitioners. Similarly to the students, the authors found the cross-department collaboration a great source of inspiration for their own research and teaching processes. For this reason, the authors would strongly endorse this approach as having a meaningful effect on staff and students' creative processes, and also on their personal development.

4. The workshops and interviews established that regardless of discipline, writing or illustration, all the students regarded writing, drawing and reading as key skills for creativity. Many of the students who participated in the interviews and workshop were able to use their creative skills interchangeably, using reading and writing to inspire visual practice and also using visual practice to inspire writing. The participating students described personal memories 
of developing these skills simultaneously when they were young but that in most cases one form eventually started to dominate their practice [3].

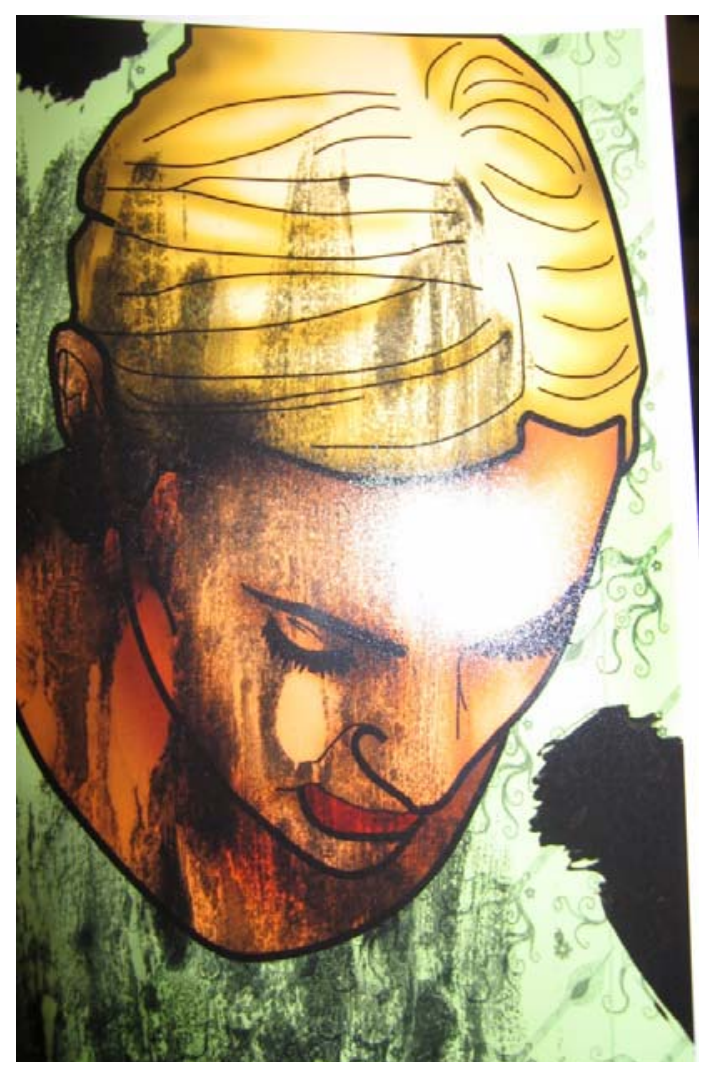

Figure 5. Student work

5. Collectively we found that these activities (informal structured learning events) helped students to articulate their practice in more depth and with more confidence and a surer sense of the knowledge they had acquired. This in turn supported their development as undergraduate researchers and enabled them to use the experiences they had gathered outside $\mathrm{HE}$ to enrich their creative processes. Students' enhanced confidence in the articulation of their creative processes can lead to greater meta-cognition, research/enquiry learning practices and self belief in their place within their discipline.

The authors have found that both the interview and the workshop, although only research tools, have the potential to function as a transformational events for the learner. In our research there was a cross over between the interviews and workshop as research events but also teaching events with the potential to impact on the students' personal development and planning. The events were not planned as learning events and the researchers did not see their role within the workshop or the interviews as that of teacher but interviewer and facilitator however, because the lines of questioning encouraged students to actively reflect on their work and make the connections between different aspects of their creative process and their personal, vocational and academic development, they were clearly relevant in terms of learning and personal, academic and vocational development. Because the researchers were talking to the students individually and in small groups about their discipline and their practice, students were provided with informal learning support and an opportunity to talk about their difficulties and concerns connected to their academic, vocational and personal lives. We argue that these events have the potential to provide a model of best practice that would be relevant to academic staff development. Our own experiences as creative practitioners and academics suggest that establishing events where academic staff can develop and discuss their creative practice and its relationship with academic research and writing would benefit academic staff in a similar way to the students who took part in this study. We argue that the model we have reported on here should be trialed further amongst undergraduates on creative practice courses and also with the staff teaching and implementing these classes at undergraduate level.

\section{B) Students' experience and perceptions of the barriers and motivators to their creative process through individual interviews and cross disciplinary group discussion.}

The purpose of these personal conversations in relation to the research project was to identify circumstances and material that has the potential to empower students with their creative process. By locating the specific mechanisms for creative processes amongst these students autobiographical experiences prior to and whilst at university, the authors aimed to discover shared experiences that support students in their creative practice and also identify possible learning experiences that would support their academic, personal and vocational development. The research found that student's creative process is motivated and supported by;

1. Understandably, confidence and belief in their (the students) ideas and their ability to execute them is important for creativity. Students vary in their degree of confidence, which can be eroded by negative criticism and/or supported by encouragement from tutors, family or friends.

2. The key to ensuring that students get the best out of academic courses lies in helping them to develop a better sense of themselves and being able to relate their individual and personal creativity to their studies. This enables them to get more out of 
their course and prepares them for their professional working lives. We also found that those students who were clearer about their interests and motivations and had a better sense of themselves were also more confident about their work and had a surer sense of ownership regarding their assessed outputs (writing and drawing).

3. Students' creativity is enhanced and inspired by positive support and encouragement from tutors, family and peers. The majority of students, regardless of discipline, described early memories of being encouraged to be creative and seemed sure that this was critical to their motivation for becoming creative practitioners.

I mean part of the reason I did it was probably because I would do something and people would go, 'Wow, wow! Look at what Ben's doing! (Transcript 1)

4. Students' creativity is improved and increased by the confidence to use personal biography as a motivator for creative work that they also find it difficult to always relate these experiences to their academic studies and vocational ambitions.

Whilst personal biographies might provide the impetus for their creativity, students also need to be able to relate this to their lives post-university in order to make sense of the purpose of their time at university. To do this, they need specific support and learning events (conversations, workshops etc) to be able to relate their creativity within a disciplinary framework.

5. Students' creativity is supported by a process through which they can follow their ideas and motivations as they develop their creative approaches. Pivotal to this is the opportunity to reflect on and discuss and debate the processes at work in their creative projects. This process is best supported by a process that provides students with opportunities to detail, discuss and develop their ideas. It is the experience of this research project that these opportunities are possibly more beneficial when outside the normal and traditional context of the classroom.

6. Students' creativity is best supported by a process through which they can follow their ideas and motivations as they develop their creative approaches. Central to this is the ability to reflect on and discuss and debate the processes at work in their creative projects

7. Students also value personal spaces in which to be creative. Students need spaces they can make their own in order to be creative. For some students (especially visual practice students), this space relates to a physical place in which they can surround themselves with the images and other stimuli that inspire them. For other students it can be related to ways of working, for example, carrying a notebook or sketchbook in which to collect and store things that they notice.

C) To develop a model of good practice for embedding personal development in a way that is relevant and meaningful to creative practice students and underpins their meta cognition.

The creative process is inextricably linked to personal development, academic achievement and vocational ambition. By creating opportunities for students to identify and reflect on their personal motivations for work and debate their creative process in a collaborative and social environment, there is an opportunity for HE to support students in the development of their creative practice. By facilitating this form of intensive reflective practice, we believe that the different factors that influence a student's creativity can be meaningfully recorded, discussed and developed. It would also allow HE the opportunity to learn about the critical moments in students' creative processes across different disciplines and provide insight into an as yet untapped source of research data that will potentially help $\mathrm{HE}$ practitioners to enhance teaching and learning across the curriculum.

Critical to improving students' academic and creative work is an opportunity to develop their ability to be critically self aware, to understand the inspirations driving their work and to provide opportunities for them to articulate their learning and creative processes. The informal learning events developed as research methods for this research project, one to one interviews and workshops, have the capacity to achieve all of these learning outcomes.

A model for embedding creativity into HE (based on our research findings) should include the following characteristics;

\section{A) Be non-assessed.}

B) Be facilitated in neutral safe spaces away from the classroom and other forms of assessment.

C) Be collaborative - bringing together students and staff from different creative disciplines.

D) Combine visual and textual approaches.

E) Encourage students to record and reflect on their ideas in note books. 
F) Promote the idea of creative practice students as researchers - providing opportunities for students to articulate and present ideas to others.

It is our belief that these characteristics also provide the basis of effective staff development events that would help with the personal, academic and vocational development of academics working in creative practice disciplines. By establishing opportunities for academic staff to discuss and reflect on their practice in cross-disciplinary groups, it may also be possible to enhance and nurture creativity in staff which may be relevant across disciplines including those not associated with creative practice.

\section{Conclusion}

Understanding the motivators and barriers that drive and diminish a student's creativity and identifying the learning and learning strategies that have the potential to enhance students' creative processes is an ongoing and complex challenge. In a time of spiralling fees, it becomes more and more important for students to understand the how their university studies will help them with their academic, vocational and personal ambitions postuniversity but PDP is often seen by students and staff as a meaningless exercise that only increases workloads without any tangible results.

This research shows that developing their confidence and identifying teaching and learning strategies that will help students to articulate and present creative processes can enable students to make the learning leaps [29] during which they learn to make the connections between;

i) Their personal interests and imaginative ideas that motivate and inspire their creativity and

ii) their creative processes and their personal, vocational and academic ambitions.

In this way, the learner may overcome fragmented views of their own creativity and also to identify more closely with the discipline of their study. Through the processes of reflection and meta-cognition, students seem to learn to recognize that they are on, and prior to HE have been on, a perpetual journey that brings them ever closer to becoming creative practitioners in their chosen fields. Identifying this journey as personal, ongoing and enhanced by the university experience can be empowering and uplifting for students. Whilst they do not initially identify themselves as being creative practitioners, the processes of self reflection, articulation and presentation of ideas seems support students by encouraging them to believe in and accept themselves as creative practitioners in their field. It is our belief that this model is also relevant in providing meaningful staff development for academics working in disciplines connected to creative practice and we suggest that similar events workshops and one-to one interviews - are potentially important opportunities for motivating, inspiring and developing staff and allowing colleagues to share experiences and best practice.

Earlier in 2010, the authors used a similar workshop format in a session with third year creative writing students and members of the University of the Third Age (U3A). The title of the workshop was 'Challenge and Sport' and the students and the over 50 s worked individually and in mixed groups to on poems, collage, autobiography and sketches that fed into the group discussions on sport as it was in the past and sport as it is now. Feedback from the workshop was positive with all the participants welcoming the opportunity to develop their creativity and share ideas and experiences in a safe but dynamic space. The workshop was funded by the Creative Campus Initiative which seeks to fulfil the aims of the 2012 Olympiad by enriching culture, celebrating diversity and bringing people together under the banner of sport. Outputs from the day were submitted to the editorial committee of the Creative Writing Anthology, produced by the University of Brighton and the University of Sussex and funded by the CCI. Two of the members of the U3A had their work published in the anthology (ref), further evidence of the potential of the workshops to boost confidence with the creative process and offer participants vocational, academic and personal development. Elizabeth Jenkins's poem 'Sport Then and Sport Now' can be seen below.

The success of the project with undergraduates and also the workshop with members of the U3A has encouraged us that this project should be extended to include academic staff and that the model of best practice we have identified contains transferrable tools that would be relevant in academic staff development events. We are currently seeking funding to embed this model in undergraduate programmes of study at the University of Brighton and also in the staff development strategy at the same institution.

\section{Sport Then and Sport Now by Elizabeth Jenkins}

\author{
Mohammed Ali - \\ you are a genius, \\ a powerhouse of
}


honed muscles.

You can sting like a bee,

dance like a King,

make us all sing

with joy in our hearts.

For we want you to win,

to win, to win, to win.

Chris Eubank -

You are a cocktail cabinet.

A weatherer of storms,

owner of a Rolls Royce, with

special features of course.

You are a Champagne drinker,

and like to eat in flash restaurants

at any time of day or night.

Your taste in music

is strange and rapacious.

You like to eat off gold plates.

Your décor is cream, scarlet and black.

You like to argue with traffic

wardens and police and

you are a cheetah for raising funds.

\section{Discussion}

This study finds that supporting students with their creative process and equipping them with the self confidence that they need to see themselves as creative practitioners requires that we focus on students' meta-reflections' (individual and group) about their learning experience. Our findings indicate that when creative practice students are given opportunities to reflect on and discuss their metamemory experiences and meta-cognitive processes that it can help them to improve their academic work.

The paper argues that the facilitation on informal structured learning events can provide the ideal scenario for providing students with threshold moments when dynamic learning leaps can occur. The paper also suggests that these workshops should be embedded in creative practice courses and in staff development strategies for academics and researchers in HEIs so that further research can be carried out to assess their potential impact on students' and staffs' creative processes and how this might influence teaching and learning of creative practice students and staff development policy in institutions nationwide.

This research raises a number of further questions about nurturing creativity in $\mathrm{HE}$ and we invite discussion on the following topics:

1. Is creativity and the teaching of it the same for all creative subjects (design, creative writing, art, performance, etc.)?

2. Can this process encourage learning across the curriculum that liberates students from the traditional approaches to their subjects?

3. How can academic staff ensure that they are creating a vision of creativity that fits with the sustainable and moral values of HE?

4. Can this process be used to empower students with the confidence to interpret the academic material that is in keeping with their own values and interests with a view to facilitating lifelong learning?

5. Why facilitate interdisciplinary collaborations between students and staff?

6. How can creative practice courses embed personal development planning in a way that is meaningful for students but not necessarily part of their assessment?

7. How can HE Institutions embed personal development planning for creative practitioners that also unblocks the creative process and helps them to identify methodologies for legitimizing practice and teaching?

\section{References}

[1] Antoniou, M., \& Moriarty, J. (2008). What academics can learn from creative writers?: Developing guidance and support for new lecturers in Higher Education. Teaching in Higher Education, 13(2), 157-167.

[2] Blakemore, H \& Reading, C (2010). "Ebb and Flow: The evolution of the Creative Practice Doctorate.". NAWE International Conference, Denver, USA.

[3] Biggs, J. (2003), Teaching for Quality Learning at University, Maidenhead: Open University Press. 
[4] Biggs, M. and Buchler, D. (2008), 'Eight criteria for practice-based research in the creative and cultural industries', Art, Design and Communication in Higher Education, 7:1, pp. 5-

[5] Clegg, P. (2008), 'Creativity and critical thinking in the globalised university', Innovations in Education and Teaching International, 45:3, pp. 20926.

[6] Cousins, G. (2009), Researching Learning in Higher Education, Abingdon: Routledge.

[7] Crosby, P. (2006), 'Self Authorship and identity in College: An interview with Marcia B

[8] Baxter Magolda, Journal of College and Character, Vol 11, No 1.

[9] Baxter Magolda', Journal of College and Character (Special Issue: Finding Wholeness: Students search for meaning and purpose in College), Part 2, 11:1-3.

[10] Csikszentmihalyi, M, (1990), Flow: The Psychology of Optimal Experience, Harper and Row.

[11] Dallow, P (2003) Representing creativeness: practice based approaches to research in creative arts Art Design and Communication in Higher Education, Vol 2

[12] Danvers, J. (2003), 'Towards a radical pedagogy: provisional notes on learning and teaching in art \& design', International Journal of Art \& Design Education, 22:1, pp. 47-57.

[13] Dillon, P. (2008), 'Pedagogy of connection and boundary crossings: methodological and epistemological transactions in working across and between disciplines', Innovations in Education and Teaching International, 45:3, pp. 255-62.

[14] Dineen, R. and Collins, E. (2004), 'Mind the gap: the promotion of creativity in art and design education', Enhancing Curricula - Conference 2, pp. 249-66. ( this is the title of the journal )

[15] Dineen, R., Samuel, E. and Livesey, K. (2005), 'The promotion of creativity in learners: theory and practice', Art, Design \& Communication, 4:3, pp. 115-73.

[16] Favell, JH \& Wellman, HM (1975) Meta cognition , Paper presented at the Annual Meeting of the American Psychological Association.

[17] Grushka, K (2005). Artists as reflective self learners and cultural communicators: an exploration of the qualitative aesthetic dimension of knowing self through reflective practice in art making,
Reflective Practice, Vol 6, No 3, August 2005, pp 353-366.

[18] Jackson, N. (2002), Guide for Busy Academics, Nurturing Creativity, The Learning and Teaching Support Network (LTSN), Generic Centre, Version 1, 4 October.

[19] Lawy (2003), 'Transformation of Person, Identity and Understanding: a case study', British Journal of Sociology of Education, 24:3, Carfax Publishing, pp. 331-45.

[20] Moriarty, J. (2007). Telling Their Story: Investigating the positive effects of a creative writing retreat on academic staff development. Unpublished Assignment for Professional Doctorate. University of Brighton.

[21] Reading, C. (2009). "Sources of Inspiration: How design students learn from museum collections and other sources of inspiration." Art, Design In Higher Education 8(12).

[22] Reading, C (2010) Exploring the relationship between writing, research and making. Section of unpublished doctorate.

[23] Moriarty, J. (2008). Leaving the blood in Using autobiography and narrative to tell the story of research into experiences with academic writing: How to get it write/right? Unpublished Research Essay. University of Brighton.

[24] Pateman, T. and Hunt, Celia (1998), The Self on The Page. Theory and Practice of Creative Writing in Personal Development, London: Jessica Kingsley, pp. 153-63.

[25] Pelias, R. (2004). A Methodology of the Heart: Evoking academic and daily life. Walnut Creek, CA: Alta-Mira Press.

[26] Quicke, J. (1996), 'Learning in Context: the Construction of an Integrated Perspective', British Journal of Sociology of Education, 17:1, pp. 103-13.

[27] Silverman, D. (1993), Interpreting Qualitative Data, London: Sage.

[28] Silverman, D. (1999), Doing Qualitative Research: A Practical Handbook, London: Sage Publications.

[29] Wisker, G, \& Kiley, M. (2006) "Learning leaps and strides: When and in what ways do doctoral students cross conceptual thresholds and achieve threshold concepts?" In Beyond boundaries: New Horizons for Research into Higher Education. 
[30] Moriarty, J and Reading, C (2011) Linking creative processes with personal, vocational and academic development in cross-disciplinary workshops. International Journal for CrossDisciplinary Subjects in Education (IJCDSE), ISSN: 20426364 (Online). 